\title{
Identification, Characterization and Expression of Heat Shock Protein 70 in Scapharca broughtonii
}

\author{
Biao $\mathrm{Wu}^{1,2}$, Menglong $\mathrm{Li}^{3}$, Libing Zheng ${ }^{1}$, Zhihong Liu ${ }^{1,2}$, Aiguo Yang ${ }^{1,2^{*}}$, Xiujun Sun ${ }^{1,2}$, \\ Liqing Zhou ${ }^{1,2} \&$ Chao Sun ${ }^{4}$
}

\begin{abstract}
${ }^{1}$ Key Laboratory of Sustainable Development of Marine Fisheries, Ministry of Agriculture, Yellow Sea Fisheries Research Institute, Chinese Academy of Fishery Sciences, Qingdao 266071, PR China

${ }^{2}$ Laboratory for Marine Fisheries Science and Food Production Processes, Qingdao National Laboratory for Marine Science and Technology, Qingdao, 266273, PR China

${ }^{3}$ Chinese Academy of Fishery Sciences, Beijing 100141, PR China

${ }^{4}$ Yantai Fisheries Research Institute, Yantai 264000, China

Correspondence: Aiguo Yang, Key Laboratory of Sustainable Development of Marine Fisheries, Ministry of Agriculture, Yellow Sea Fisheries Research Institute, Chinese Academy of Fishery Sciences, Qingdao 266071, PR China. Email: yangag@ysfri.ac.cn
\end{abstract}

Received: July 16, 2018

doi:10.5539/jmbr.v8n1p167
Accepted: August 15, 2018

Online Published: November 30, 2018

\begin{abstract}
As one crucial member of heat shock proteins (HSPs) family, HSP70s play many important roles in a large amount of physiological processes including immune response. However, information regarding HSP70 in ark shell Scapharca broughtonii is still rather limited. Here the full-length cDNA of HSP70 gene (named SbHSP70) of $S$. broughtonii was identified by using reverse transcription PCR (RT-PCR) and rapid amplification ends (RACE) methods. The $S b H S P 70$ cDNA was 2423 bp in length containing a 5' untranslated region (UTR) of $131 \mathrm{bp}, 3^{\prime}$-UTR of $330 \mathrm{bp}$, and an open reading frame (ORF) of $1962 \mathrm{bp}$ which encodes a peptide of 653 amino acids. The multiple alignment and phylogeny analysis showed that the $S b H S P 70$ shared high homology sequence with other mollusk species, and clustered together with gastropods to form a sister group. The mRNA expression profiles of SbHSP70 in tissues of foot, gill, mantle, adductor muscle, haemocytes and hepatopancreas analyzed by quantitative real-time PCR (qRT-PCR) suggested the mRNA transcripts of SbHSP70 distributed in all the examined tissues, and the highest expression level was observed in foot, and a significant difference could be detected between gill and adductor muscle $(p<0.05)$, no significant difference among the gill, mantle and hemocytes $(p>0.05)$. Its dynamic change during the early stage of larvae showed that it could be transferred from parent and may be involved in some key developmental process. What's more, Vibrio anguillarum challenge resulted in regular change of expression of $S b H S P 70 \mathrm{mRNA}$, indicating $S b H S P 70$ actively participated in the immune response process.
\end{abstract}

Keywords: Scapharca broughtonii; HSP70; gene cloning; express profile

\section{Introduction}

Heat shock proteins (HSPs), with a highly conserved polypeptide of structure and widely existing in prokaryotic and eukaryotic cells, acted as molecular chaperons to maintain the proper folding or refolding protein, which playing lots of important roles not only in normal condition but also in the continuation of life under stress. Some stress factors such as heat, heavy metal and pathogens, could destroy the advanced structure of proteins and disrupt the cell status, which might induce the increase of HSPs expression level (Mager et al., 2000; Lewis et al., 2001; Li \& Guy, 2001; Snyder et al., 2001; Sørensen \& Loeschcke, 2001; Rizhsky et al., 2002). Under normal circumstances, HSPs are involved in maintaining protein conformation, protecting cell life activities, folding and transporting generated proteins, repairing mis-folded proteins, helping degradation of denatured proteins and stabling cytoskeleton as a molecular chaperone in cells (Morimoto et al., 1997; Fink, 1999). However, when facing the stress condition, organisms would massively produce HSPs to prevent from the accumulation of denatured proteins, transport immature proteins to target organelles and improve the stress tolerance to protect organisms from damaging (Mayer \& Bukau, 2005; Tanaka et al., 2007). Because of their important biological functions, HSPs have been becoming more and more popular research objects in many fields. 
As one member of HSPs family, HSP70 is nearly the most important, conserved and widely studied protein in many organisms. HSP70 mRNA could be detected in nearly all tissues of a certain organism, widely distributing in nucleus, cytoplasm, endoplasmic reticulum and mitochondria (Boston et al., 1996; Kiang \& Tsokos, 1998; Renner \& Waters, 2007). In recent years, some studies on the immune function of HSP70 have been reported in a few mollusks species. However, to our knowledge, information about HSP70 in the ark shell Scapharca broughtonii is extremely limited.

The S. broughtonii, due to its abundant protein, various vitamins contents, delicious tastes, and high economic value, has become one of the most commercially and ecologically important shellfish in China, Korea and Japan in the last twenty years. Unfortunately, the death of $S$. broughtonii in a large scale, especially at the juvenile stages, made the natural resources of S. broughtonii decrease dramatically in the recent years (Bai et al., 2016). Among many possible affecting factors resulting in the massive death of $S$. broughtonii, the environmental deterioration and germ plasm degradation in China are two important reasons. In order to prevent the enormous economic loss caused by diseases outbreak in the breeding like Scallops, strengthening the study of immune mechanisms is of considerable economic significance. However, study regarding the immune of $S$. broughtonii was limited, except for few immune-related genes, like ferritin (Zheng et al., 2016), MnSOD (Zheng et al., 2015) and big defensin (Li et al., 2012).

The main objectives of this present study were to clone the HSP70cDNA of S. broughtonii (designated SbHSP70), investigate mRNA expression of SbHSP70 in different tissues and response to challenge of Vibrio anguillarum, for understanding the immune function of SbHSP70.

\section{Materials and Methods}

\subsection{Animals, Challenge Experiments and Sampling}

Healthy ark shells $S$. broughtonii with shell length of 50-70 $\mathrm{mm}$ were collected from an aquaculture area located at Qingdao (Shandong Province, China). The collected ark shells were maintained in tanks containing aerated seawater at $20^{\circ} \mathrm{C}$ for 7 days before the experimental treatment. The larvae at different developmental stages were collected in a shellfish hatchery. The different stage larvae were sampled at $0,1 / 24,1 / 12,1 / 8,1 / 2,2 / 3,3 / 4,7 / 6,2$, $3,5,6,8,9,10,11,12,13$ and 22 days after fertilization, respectively.

The bacterial challenge experiment was carried out as described by Zheng et al. (2016). In brief, ark shells were randomly selected and then divided into experimental and control groups. The adductor muscle of each individual in the challenged group was injected with $50 \mu \mathrm{l}$ of live Gram-negative bacterium $V$. anguillarum suspensions $\left(\mathrm{OD}_{600}=0.4,1\right.$ absorbance unit $\left.=5 \times 10^{8} \mathrm{bacteria} / \mathrm{ml}\right)$, while each of the control group received an injection of $50 \mu \mathrm{l}$ of PBSwith $\mathrm{pH}$ 7.2. After injection, all ark shells were taken back to the aerated seawater tanks.

Three random individuals sampled at $0,4,8,12,24,32$ and $64 \mathrm{~h}$ post-injection were combined as an anytical sample. Different tissues including gill, adductor muscle, foot, hepatopancreas and mantle were obtained from samples to clone the full-length cDNA of SbHSP70 and analyze its expression profile. In particular, haemocytes were collected by hemolymph withdrawal followed by centrifugation according to a previously reported method (Zheng et al., 2015). All the sample tissues were dissected in liquid nitrogen rapidly and then stored at $-80{ }^{\circ} \mathrm{C}$ for total RNA extraction.

\subsection{RNA Extraction and cDNA Synthesis}

Total RNA was extracted from the six sampled tissues (mentioned above) by using Trizol Reagent (Invitrogen, USA) and the genetic DNA contamination in the extracted RNA was eliminated using RQ1 RNase-free DNase (Promega, USA) according to method as described by Wu et al. (2015). The RNA quality was assessed by the ratio of $\mathrm{A}_{260} / 280$ detected using a NanoDrop Micro-Spectrophotometer (Eppendorf, USA) and integrity was examined through $1.5 \%$ agarose gel electrophoresis and then RNA was stored at $-80^{\circ} \mathrm{C}$ until further use. Frist-strand cDNA was synthesized using SMARTer ${ }^{\mathrm{TM}}$ RACE Amplication Kit (TaKaRa, USA) according to the protocol described by the manufacturer.

\subsection{Cloning the Full-Length cDNA of SbHSP70}

A transcriptome library of healthy $S$. broughtonii has been constructed in advance by authors, where a partial-sequence of HSP70 was found. The full-length cDNA of SbHSP70 was cloned based on this sequence by using reverse transcriptase PCR (RT-PCR) and rapid amplification ends (RACE) technology. The primers (HSP-F and HSP-R) to amplify the first sequence were designed on the basis of the known partial-sequence by the primer premier 5.0 software. Based on the obtained sequence above, the primers HSP-3F and HSP-5R for RACE amplification were designed to get the full-length cDNA of SbHSP70 using3'-Full RACE Core Set Ver. 2.0 kit and 5'-Full RACE kit (TaKaRa) according to the manufacturer's instructions, respectively. In detail, the 5'-RACE of 
the $\operatorname{SbHSP70}$ cDNA was performed using primers UPM $(10 \times$ Universal Primer A Mix $)$ and HSP-5R in a $50 \mu 1$ of reaction volume, containing $41.5 \mu \mathrm{l}$ Master Mix (34.5 $\mu \mathrm{l}$ of PCR-grade water, $5.0 \mu \mathrm{l}$ of $10 \times \mathrm{PCR}$ buffer, $1.0 \mu \mathrm{l}$ of dNTP $(10 \mathrm{mM}), 1.0 \mu \mathrm{l} 50 \times$ Advantage 2 Polymerase Mix), $2.5 \mu \mathrm{l}$ of 5 '-RACE-Ready cDNA, $1.0 \mu \mathrm{l}$ HSP-5R (10 $\mu \mathrm{M}$ ), and $5 \mu \mathrm{UPM}$. The PCR reaction profile was $94{ }^{\circ} \mathrm{C} 30 \mathrm{~s}, 66^{\circ} \mathrm{C} 30 \mathrm{~s}, 72{ }^{\circ} \mathrm{C} 2 \mathrm{~min}$ for $27 \mathrm{cycles}$. The 3 '-RACE was carried out using primers HSP-3F and UPM, the PCR reaction volume and profile were the same as the 5'-RACE performance. All the amplified products were gel-purified and cloned into $\mathrm{pMD}^{\mathrm{TM}} 18$-Tsimple vector (TaKaRa) according to the instruction. The vectors were transformed into the competent Escherchia coli Top 10 cells, and positive clones were screened via colony PCR for sequencing and then the sequences were verified and assembled for further analysis.

\subsection{Sequence Analysis}

The open reading frame (ORF) and amino acid sequence were inferred from SbHSP70 cDNA using the software DNAStar 7.0, the protein motifs feature was predicted by Simple Modular Architecture Research Tool (http://smart.embl-heidelberg.de/). The molecular weight and theoretical isoelectric point were predicted with ProtParam tool (http://web.expasy.org/protparam/). The presence and location of signal peptide was predicted by SignalIP 4.0 Server (http://www.cbs.dtu.dk/services/SignalP/). The prediction of glycosylation site was done through applying the NetNglyc 1.0 server. The homologues were analyzed by the BLASTP program at the National Center for Biotechnology Information (http://www.ncbi.nlm.nih.gov/blast). Multiple alignment of SbHSP70 was performed using the software DNAman 8.0. A phylogenetic tree was constructed using the Neighbor-Joining method by Mega 5.0 and the tree topology was tested using bootstrap of 1000 replications.

\subsection{Tissue Distribution of SbHSP70 mRNA and Its Expression Analysis}

Quantitative real-time PCR (qRT-PCR) was employed to detect the SbHSP70 mRNA expression pattern in the tissues, dynamic changes during the early developmental stage and after $V$. anguillarum challenge. The qRT-PCR experiment was performed on an ABI 7500 Real-time PCR System (Applied Biosystems). The cDNA quality was normalized by $\beta$-actin gene of S. broughtonii. The specific primers Q-F/R for qRT-PCR amplification were also designed according to $S b H S P 70$ cDNA sequence by primer premier 5.0. The qRT-PCR were performed in a reaction volume of $20 \mu \mathrm{l}$ in triplicates, containing $10 \mu \mathrm{l}$ SYBR Premix Ex TaqII $(2 \times), 0.4 \mu \mathrm{l}$ ROX Reference Dye II $(50 \times), 0.4 \mu \mathrm{l}$ of each primer $(10 \mathrm{mM})(\mathrm{Q}-\mathrm{F} / \mathrm{R}$ in table 1$), 2.0 \mu \mathrm{l}$ of diluted cDNA $(5 \times)$, and $6.0 \mu \mathrm{l}$ of PCR-grade water. The thermal profile for qRT-PCR was as follow: $95{ }^{\circ} \mathrm{C}$ for $30 \mathrm{~s}$ followed by 38 cycles of $95^{\circ} \mathrm{C}$ for $5 \mathrm{~s}$ and $60^{\circ} \mathrm{C}$ for $30 \mathrm{~s}$. The analysis of dissociation curves after thermocycling was performed to confirm the amplification specificity of $S b H S P 70$ gene and $\beta$-actin gene. In a 96-well plate, each sample was amplified in triplicate along with the internal control gene. The blank sample with minimal $\Delta C_{\mathrm{T}}$ value was used as the calibrator. The $\Delta C_{\mathrm{T}}$ for each sample was subtracted from the $\Delta C_{\mathrm{T}}$ of the calibrator, and the difference was called $\Delta \triangle C_{\mathrm{T}}$ value. The expression level of the $S b H S P 70$ gene related to the $\beta$-actin gene was determined by the $2^{-} \triangle \triangle \mathrm{Ct}$ method (Livak and Schmittgen, 2001). All the data were given in terms of relative mRNA expressed as means \pm SD (standard deviation of the means. Differences were considered to be significant at $p<0.05$, highly significant at $p<0.01$.

Table 1. The primers used in the experiment

\begin{tabular}{ll}
\hline primers & $\mathbf{5}$ '-3'sequence \\
\hline $10 \times$ Universal Primer A Mix & CTAATACGACTCACTATAGGGCAAGCAGTGGTATCAACGCAGAGT \\
$($ UPM $)$ & CTAATACGACTCACTATAGGGC \\
HSP-F & CCCTGCTTACTTTAACGACTC \\
HSP-R & GACAATGGGATTACAGACACC \\
HSP3F & TATCCCTGGGTATTGAGACTGCT \\
HSP5R & CGCCCAAATGAGTGTCACCTGATGTT \\
$\beta$-actin-F & GGTTACACTTTCACCACCACAG \\
$\beta$-actin-R & ACCGGAAGTTTCCATACCTAAGA \\
Q-F & AACCCACTGCCGCTGCTA \\
Q-R & AAATCTTCACCGCCCAAA \\
\hline
\end{tabular}




\section{Results}

\subsection{Characterization of SbHSP70 cDNA}

A nucleotide sequence with final length of $2423 \mathrm{bp}$ representing for the complete cDNA sequence of $S b H \mathrm{SP} 70$ gene was obtained by assembling all the amplified partial fragments amplified by RT-PCR and RACRE. The cDNA sequence was submitted to GenBank with assigned accession number KX383795. The main characterization of this sequence ofSbHSP70 cDNA is shown in Figure 1. The full-length sequence of $S b H S P 70$ cDNA contained a 5'-untranslated region (UTR) of $131 \mathrm{bp}$, a 3'-UTR of $330 \mathrm{bp}$ with a canonical polyadenylation signal sequences AATAAA and a poly (A) tail, and an open reading frame (ORF) of 1962 bp encoding a polypeptide of 653 amino acids with the predicted molecular mass of $71.33 \mathrm{kDa}$ and theoretical isoelectric point of 5.36. There was no signal peptide found in the N-terminal portion of this gene. Five glycosylation sites (NRTT, NPTN, NDSQ, NKSI, NTTV) were predicted in the amino acid sequence. Three highly conserved sequences of HSP70 family were found among the putative amino acids, they were IDLGTTYS (11-18), IFDLGGGTFDVSIL (174-187), IVLVGGSTRIPRIQK (311-325), respectively. SMART program analysis revealed that there was an MreB-MbI (expand the abbreviation) domain with 266 (118-384) aa in this sequence.

\subsection{Homology and Phylogenetic Analysis of SbHSP70}

The deduced amino acid sequence of $S b H S P 70$ showed high similarity in sequence and structural features with some reported HSP70 from mollusks (Figure 2). Among these sequences, the highest identity of $96 \%$ was shared with Tegillar cagranosa and followed identities of 92\% shared with Pernaviridis, $91 \%$ with Mytilus galloprovincialis, M. coruscusand Azumapecten farreri, 90\% with Crassostrea gigas, $89 \%$ with C. ariakensis, 86\% with Argopecten irradians. Besides these, SbHSP70 also shared high identities with gastropods, such as 89\% of Haliotis diversicolor, $88 \%$ with Biomphalaria glabrata and $H$. discus hannai.

The alignment analysis with other HSP70 isolated from the chosen representative species in this study revealed that $S b H S P 70$ was highly conserved compared to other HSP70 sequence, and the important sites possessed in HSP70 family were also conserved.

The result of analysis with NJ phylogenetic tree (Figure 3) agreed with that of multiple alignments. From this figure, we can see that the phylogenetic tree can be divided into two big clades: one is the invertebrate clade, and the other is the vertebrate clade. Among the invertebrate clade, SbHSP70 clustered together with HSP70 of $T$. granosa, the HSP70 of bivalve formed a sister group with gastropods HSP70, HSP70 from crustacean was the second group. The relationships displayed in the phylogenic tree were in good agreement with traditional taxonomy.

\subsection{Tissue-specific and developmental-specific expression of SbHSP70 in normal S. broughtonii}

$S b H S P 70$ expression levels in different tissues is shown as Figure 4. The results showed that the $S b H S P 70$ mRNA was ubiquitously expressed in all sampled tissues of $S$. broughtonii. The highest level was approximately 2737 -fold $(p<0.01)$ in the foot, while the lowest one was that in hepatopancreas, about 1054-fold and 1199-fold $(p<0.05)$ in gill and haemocytes according to hepatopancreas, respectively. In addition, the difference of SbHSP70 expression between gill and adductor muscle was statistically significant $(p<0.05)$, there was no significant difference in the HSP expression between the gill, mantle and haemocytes $(p>0.05)$. And also, the expression profile during the early developmental stages of the larvae showed that the dynamic trend was decreased initially till $12 \mathrm{~h}$ and then increased to highest at $9 \mathrm{~d}$, following the second decrease (Figure 5). Among the detected stage, the expression dose changed sharply at the stage of 9 days and 22 days.

\subsection{Transcriptional Responses of SbHSP70 to Bacterial Challenge}

qRT-PCR analysis was performed to examine the temporal expression pattern of $S b H S P 70$ after $V$. anguillarum challenge, with $\beta$-actin as the internal control. All the results were shown in Figure 6. The results indicated that there were apparent changes in examined tissues. In the adductor muscle and hepatopancreas, the SbHSP70 dynamic expression had the same trend which tended to increase firstly and followed by decline and then rise, with the first expression peak level of 2.23- and 3.21-fold $(p<0.05)$ at $4 \mathrm{~h}$, and the second peak in the adductor muscle at $32 \mathrm{~h}$ (2.46-fold, $p<0.05$ ) and in the hepatopancreas at $24 \mathrm{~h}$ (4.84-fold, $p<0.05$ ) compared to that at $0 \mathrm{~h}$, respectively. In addition, $S b H S P 70$ in other examined tissues showed a general trend of declining first and then rising, but most expression were lower than those of the control group at $0 \mathrm{~h}$, with the expression going down at $4 \mathrm{~h}$, and then a significant increase appearing expression peak of 1.21-, 0.50-, 0.76-fold $(p<0.05)$ at $8 \mathrm{~h}$ in the foot, gill and mantle, respectively. After that, the $S b H S P 70$ mRNA in those tissues showed declining trend. Besides the above results, the SbHSP70 mRNA in haemocytes gave a special response to bacterial challenge that the expression declined sharply before $8 \mathrm{~h}$ and then went up to the same level as that ofcontrol group at following time points. 
1 gatcaaaact gttctgtata tttattttac ataaacactc aac ATG TCT AAG AAB TCA AAB CAA GCT ATC GGA ATT GAT TTA

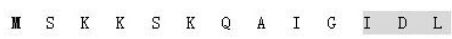
83 GGA ACA ACA TAC TCC TGT GTG GGT GTA TTC CAA CAT GGT AAA GTA GAA ATA ATT GCC AAC GAC CAA GGT AAC AGA

$\begin{array}{lllllllllllllllllllllllllllllllllll}G & T & T & Y & S & C & V & G & V & F & Q & H & G & K & V & E & I & I & A & \mathbb{N} & D & Q & G & \underline{\underline{N}} & \mathbb{R}\end{array}$ 158 ACT ACC CCC AGT TAT GTA GCC TTC ACA GAT ACA GAA CGT CTG ATT GGT GAT GCT GCC AAG AAC CAA GTG GCC ATG

$\begin{array}{llllllllllllllllllllllllllllll}\underline{T} & T & P & S & Y & V & A & F & T & D & T & E & R & L & I & G & D & A & A & K & N & Q & V & A & M\end{array}$ 233 AAT CCA ACA AAC ACT ATA TTT GAT GCC AAG CGT TTA ATT GGA AGA AAA TTT ACT GAT CAG TCG GTC CAA TCC GAC

$\begin{array}{lllllllllllllllllllllllllll}\mathbb{N} & P & T & \mathbb{N} & T & I & F & D & A & K & R & L & I & G & R & K & F & T & D & Q & S & V & Q & S & D\end{array}$ 308 ATG AAA CAC TGG CCA TTT ACA GTT ATA AGT GAC GGA GGC AAG CCT AAA ATT CAA GTT GAC TAC AAA GGA GAA ACA $\begin{array}{lllllllllllllllllllllllllll}M & K & H & \text { II } & P & F & T & V & I & S & D & G & G & K & P & K & I & Q & \Downarrow & D & Y & K & G & E & T\end{array}$ 383 AAA TCA TTT TAT CCT GAA GAA GTA TCC TCC ATG GTT CTG AAC AAA ATG AAA GAA ACT GCA GAA GCT TAT CTT GGT $\begin{array}{llllllllllllllllllllllllllll}K & S & F & Y & P & E & E & V & S & S & \text { II } & \text { V } & \text { L } & \text { N } & \text { K } & \text { II } & \text { K } & \text { E } & \text { T } & \text { A } & \text { E } & \text { A } & \text { Y } & \text { L } & G\end{array}$ 458 TTG ACA ATC TCA AAT GCT GTA GTC ACA GTC CCT GCT TAC TTT AAC GAC TCT CAG CGT CAA GCA ACA AAA GAT GCT $\begin{array}{lllllllllllllllllllllllllll}L & T & I & S & \mathbb{N} & A & V & V & T & V & P & A & Y & F & \underline{N} & D & S & Q & R & Q & A & T & K & D & A\end{array}$ 533 GGT ACT ATT TCA GGA ATG AAT GTT TTG CGT ATT ATC AAT GAA CCC ACT GCC GCT GCT ATT GCA TAT GGT CTT GAC

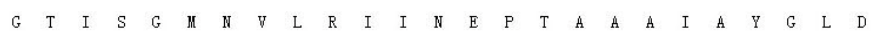
608 AAA AAG GTT GGT GGT GAA AGA AAT GTT CTG ATC TTT GAT CTT GGT GGA GGT ACC TTC GAT GTC TCT ATA CTA ACA

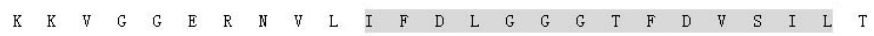
683 ATT GAA GAT GGT ATT TTT GAA GTA AAA TCA ACA TCA GGT GAC ACT CAT TTG GGC GGT GAA GAT TTT GAC AAT CGT

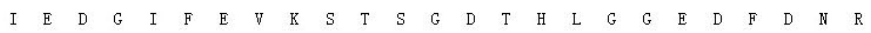
758 ATG GTT AaT CAT TTT ATA AAT GAA TTC AAA CGC AAA CAC AAA AAG GAT ATT TCA GAT AAT AAG AGA GCA GTT AGA $\begin{array}{llllllllllllllllllllllllllll}\text { II } & V & \mathbb{N} & \mathrm{H} & \mathrm{F} & \mathrm{I} & \mathbb{N} & \mathrm{E} & \mathrm{F} & \mathrm{K} & \mathrm{R} & \mathrm{K} & \mathrm{H} & \mathrm{K} & \mathrm{K} & \mathrm{D} & \mathrm{I} & \mathrm{S} & \mathrm{D} & \mathbb{N} & \mathrm{K} & \mathrm{R} & \mathrm{A} & \mathrm{V} & \mathrm{R}\end{array}$ 833 CGT CTC AGA ACC GCT TGT GAA AGA GCA AAG AGA ACC CTC TCT TCC AGT ACA CAG GCT AGT GTT GAA ATT GAT TCC $\begin{array}{llllllllllllllllllllllllllllllllll}R & L & R & T & A & C & E & R & A & K & R & T & L & S & S & S & T & Q & A & S & V & E & I & D & S\end{array}$ 908 TTG TAT GAG GGT ATT GAC TTT TAC ACA AGT ATC ACC AGA GCT CGT TTT GAA GAA TTG AAT GCA GAT CTT TTC CGT

$\begin{array}{llllllllllllllllllllllllllllllll}L & Y & E & G & I & D & F & Y & T & S & I & T & R & A & R & F & E & E & L & N & A & D & L & F & R\end{array}$ 983 GGT ACC TTG GAA CCT GTA GAG AAA GCT TTG AGA GAT GCT AAG GCA GAC AAG GCA ACT ATT CAT GAC ATT GTA CTT $\begin{array}{lllllllllllllllllllllllllll}G & T & L & E & P & V & E & \mathbb{R} & A & L & R & D & A & K & A & D & K & A & T & I & H & D & I & V & L\end{array}$ 1058 GTT GGT GGT TCC ACC AGA ATT CCA AGA ATC CAG AAA CTG TTG CAG GAT TTC TTC AAT GGT AAA GAA CTG AAC AAG

$\begin{array}{lllllllllllllllllllllllllll}V & G & G & S & T & R & I & P & R & I & Q & K & L & L & Q & D & F & F & \mathbb{N} & G & K & E & L & \underline{\underline{N}} & \mathbb{K}\end{array}$ 1133 TCC ATC AAT CCT GAT GAA GCT GTA GCA TAC GGA GCA GCT GTC CAA GCG GCC ATT TTG TCT GGT GAT CAA TCA GAA

$\begin{array}{lllllllllllllllllllllllllll}S & \text { I } & N & P & D & E & A & \text { V } & A & Y & G & A & A & V & Q & A & A & I & L & S & G & D & Q & S & E\end{array}$ 1208 GAA GTC CAG GAT CTT CTC TTG TTG GAT GTG GCT CCA TTA TCC CTG GGT ATT GAG ACT GCT GGT GGT GTG ATG ACA

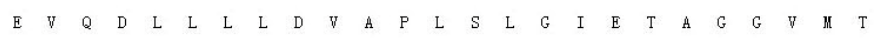
1283 ACA CTG ATC AAA CGT AAC ACA ACT GTC CCA ACC AAA CAA ACC CAG ACC TTC ACC ACA TAT TCT GAC AAT CAG CCA

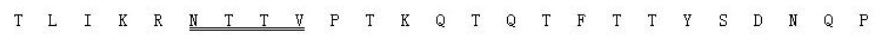
1358 GGT GTA CTT ATC CAA GTT TTT GAG GGA GAA CGT GCA ATG ACC AAG GAC AAC AAC ATC CTT GGT AAA TTT GAA CTG $\begin{array}{llllllllllllllllllllllllllll}G & V & L & I & Q & V & F & E & G & E & R & A & M & T & K & D & N & \mathbb{N} & \text { I } & \text { L } & G & K & F & E & L\end{array}$ 1433 ACT GGT ATT CCA CCA GCA CCT CGT GGT GTT CCT CAA ATT GAA GTT ACC TTT GAT ATT GAT GCT AAT GGT ATC TTG

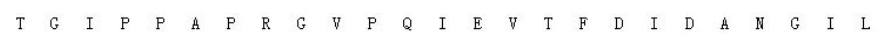
1508 AAT GTA CAT GCA GTA GAC AAG AGT ACT GGA AAA GAA AAT AAG ATC ACC ATT ACA AAT GAC AAA GGT CGT CTC AGC

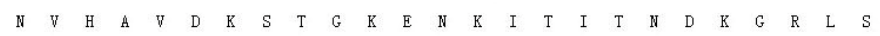
1583 AAA GAG GAT ATC GAC AGA ATG GTT AAC GAT GCA GAA AAA TAC AAG GCT GAA GAT GAA AAA CAA AGG GAC AGA ATT $\begin{array}{llllllllllllllllllllllllllll}\mathrm{K} & \mathrm{E} & \mathrm{D} & \mathrm{I} & \mathrm{D} & \mathrm{R} & \mathbb{M} & \mathrm{V} & \mathbb{N} & \mathrm{D} & \mathrm{A} & \mathrm{E} & \mathrm{K} & \mathrm{Y} & \mathrm{K} & \mathrm{A} & \mathrm{E} & \mathrm{D} & \mathrm{E} & \mathrm{K} & \mathrm{Q} & \mathrm{R} & \mathrm{D} & \mathrm{R} & \mathrm{I}\end{array}$ 1658 GGA GCT AAG AAT GGA CTG GAA AGT TAT TCA TTC CAA ATG AAA TCC ACA GTG GAA GAT GAG AAA TTG AAG GAC AAA

$\begin{array}{llllllllllllllllllllllllllllllllll}G & A & K & \mathbb{N} & G & L & E & S & Y & S & F & Q & M & K & S & T & V & E & D & E & K & L & K & D & K\end{array}$ 1733 ATT TCT GAA GAT GAT AAG AAA TGC ATT ACT GAG AAA TGT GAT GAA ATC ATC AAG TGG TTA GAT GCC AAT GGT CTG

$\begin{array}{llllllllllllllllllllllllllll}I & S & E & D & D & K & K & C & I & T & E & K & C & D & E & I & I & K & \| & L & D & A & \mathbb{N} & G & L\end{array}$ 1808 GCA GAG AAA GAG GAG TTT GAA CAC AAA CAG AAG GAA TTA GAA GGT GTC TGT AAT CCC ATT GTC ACC AAG TTG TAT $\begin{array}{lllllllllllllllllllllllllllll}A & E & K & E & E & F & E & H & K & Q & K & E & L & E & G & V & C & N & P & I & V & T & K & L & Y\end{array}$ 1883 CAG GGT GCT GGA GGA GCT GCC GGA GCT GGT GGT ATG CCT GGA GGA TTC CCA GGT GGT GCT GGA GGT CAA CAA CAA

$\begin{array}{lllllllllllllllllllllllllllllllll}Q & G & A & G & G & A & A & G & A & G & G & I & P & G & G & F & P & G & G & A & G & G & Q & Q & Q\end{array}$ 1958 CAG TCC AGT GGG GGT AGC GGT GGA CCA ACT ATT GAA GAA GTT GAT TAA atacatgaga tttatataat aacaaactta

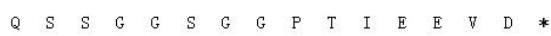

2036 ttctattcag ttccaccagt aaaatttgtt tagtaattca ttatttattt gattgttttc atagtttcaa ctgtttggat ggtggtaatt 2126 ttatatctac aaca taattt atttaatttc aaatcattaa cagtgacatc attacaatca ttttgttgaa agaacag tgt caaaattaat 2216 ggcagttacc aaaacttcac a aa taaagtt tgcattttaa catcctattc aactagtgtc agaaagaaca aataaaaaag accaaacaat 2306 acagtt tatt tgaagaagaa aaaaaaaaaa

Figure 1. Nucleotide and deduced amino acid sequence of SbHSP70. The letters in box are start codon (ATG) and stop codon (TGA), respectively; the letters with underline indicates the polydenylation signal sequence

(AATAAA) and poly(A) tail, respectively. The double underline indicates the glycosylation sites; the conserved regions are shown with shadow 

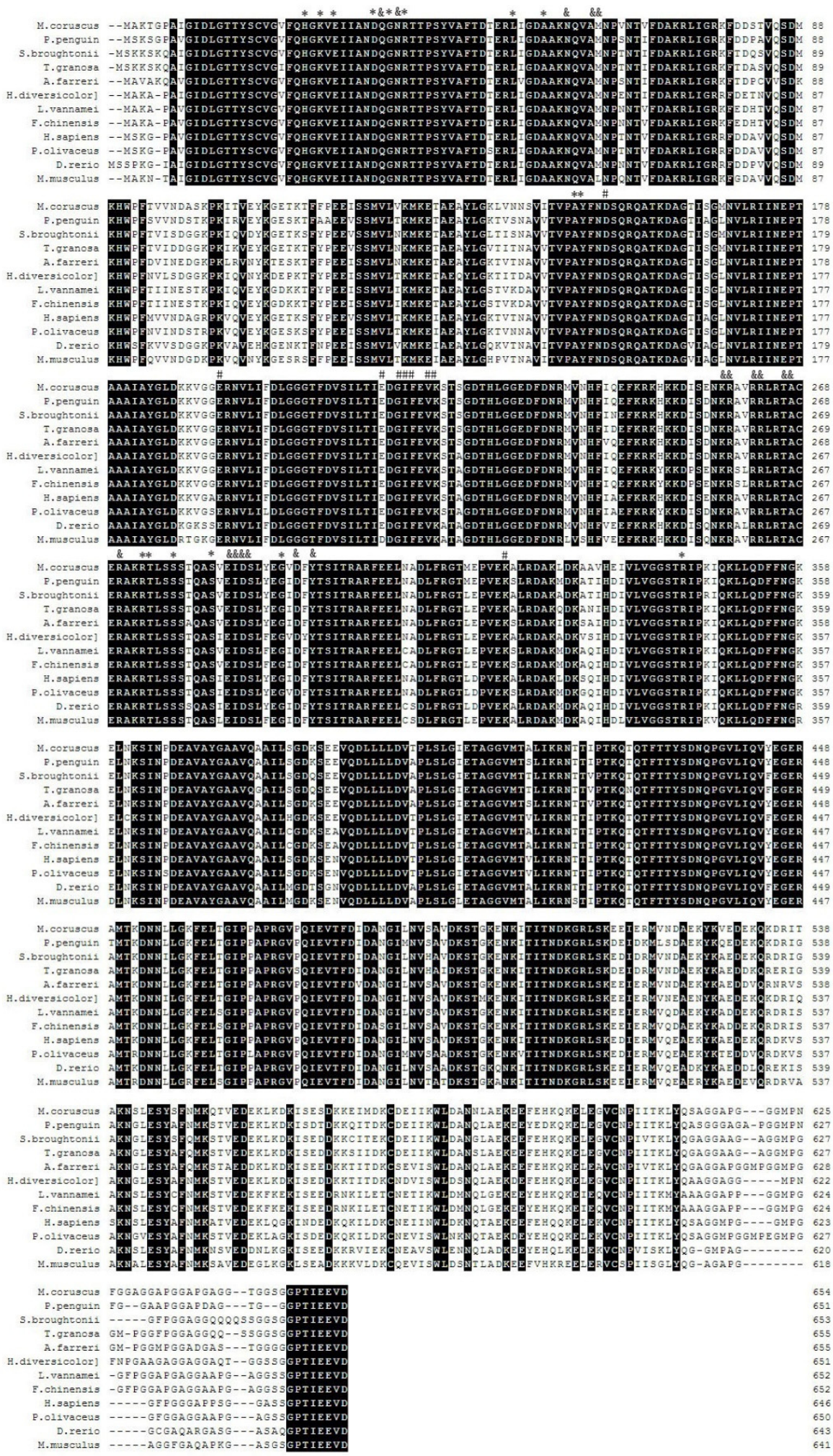

654
651
653
655
655
655
652
652
646
650
643
641

Figure 2. The Multiple alignment of the amino acid sequence of the HSP70 from S. broughtonii with other animals. The "\#" indicates the SBD connector, the"\&" shows the interaction sites between BAG and HSP70, and the"*" shows the interaction sites of NEF/HSP70. GenBank accession numbers of HSP70 from representative species were Tegillarca granosa (AFH66950.1), Chlamys farreri (AAO38780.1), Mytilus coruscu (AGY56119.1), Pteria penguin (ABJ97377.1), Haliotis diversicolor (ACO36047.1), Litopenaeus vannamei (AAT46566.1).

Fenneropenaeus chinensis (AAW71958.1), Homo sapiens (AAK17898.1), Paralichthys olivaceus (AAC33859.1), Mus musculus (AAC84169.1), Danio rerio (AAH56709.1) 


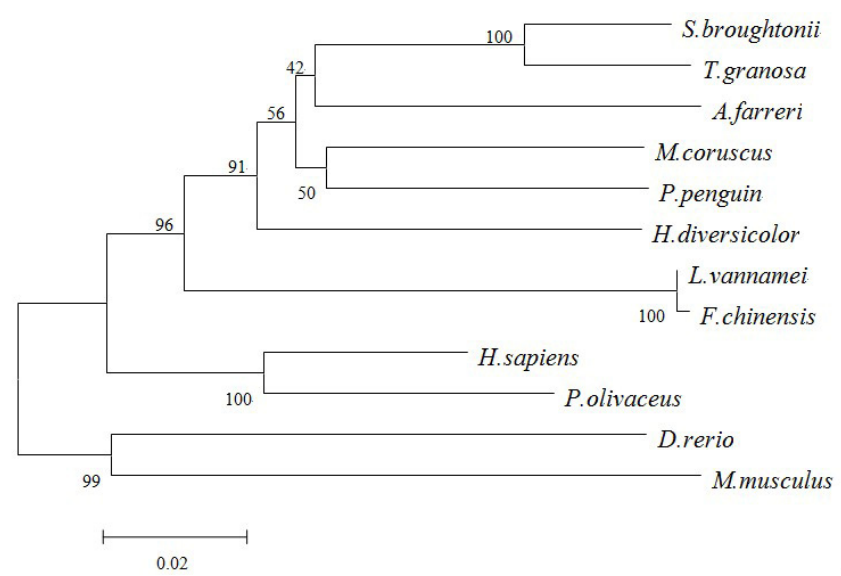

Figure 3. The Phylogenetic tree of the HSP70 constant region amino acid sequences between S. broughtonii and other species. The reliability of the branching was tested by bootstrap re-sampling (1000 pseudo-replicates).

GenBank accession numbers of HSP90s used were T. granosa (AFH66950.1), C. farreri (AAO38780.1), M. coruscu (AGY56119.1), P. penguin (ABJ97377.1), H.diversicolor (ACO36047.1), L. vannamei (AAT46566.1). F. chinensis (AAW71958.1), H. sapiens (AAK17898.1), P. olivaceus (AAC33859.1), M. musculus (AAC84169.1), D. rerio (AAH56709.1)

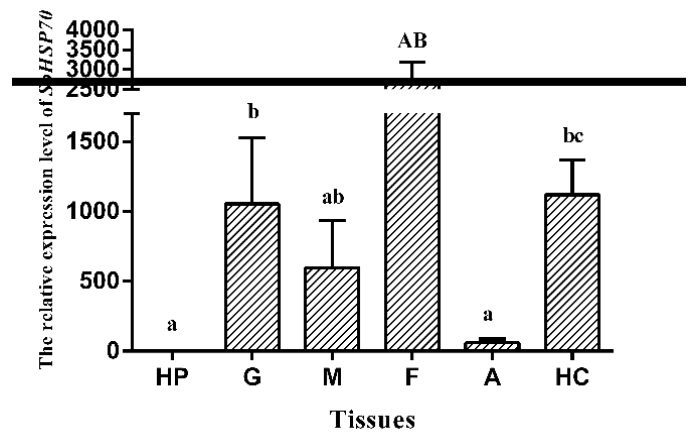

Figure 4. Distribution of $S b H S P 70$ gene in different tissues. Vertical bars represent the mean \pm S.D. $(\mathrm{N}=3)$. The columns with different letters indicated extremely significance $(P<0.01)$ between groups. F: Foot, G: Gill, M:

Mantle, HP: Hetapopancreas, A: Adductor muscle, HC: Haemocytes

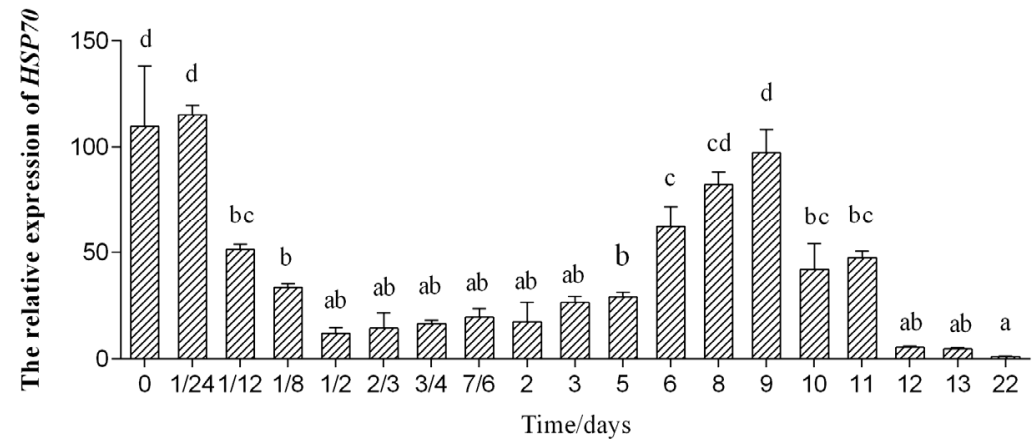

Figure 5. HSP70 expression level in different developmental time of larvae. Different lowercase letters indicate significant difference $(\mathrm{p}<0.05)$ 

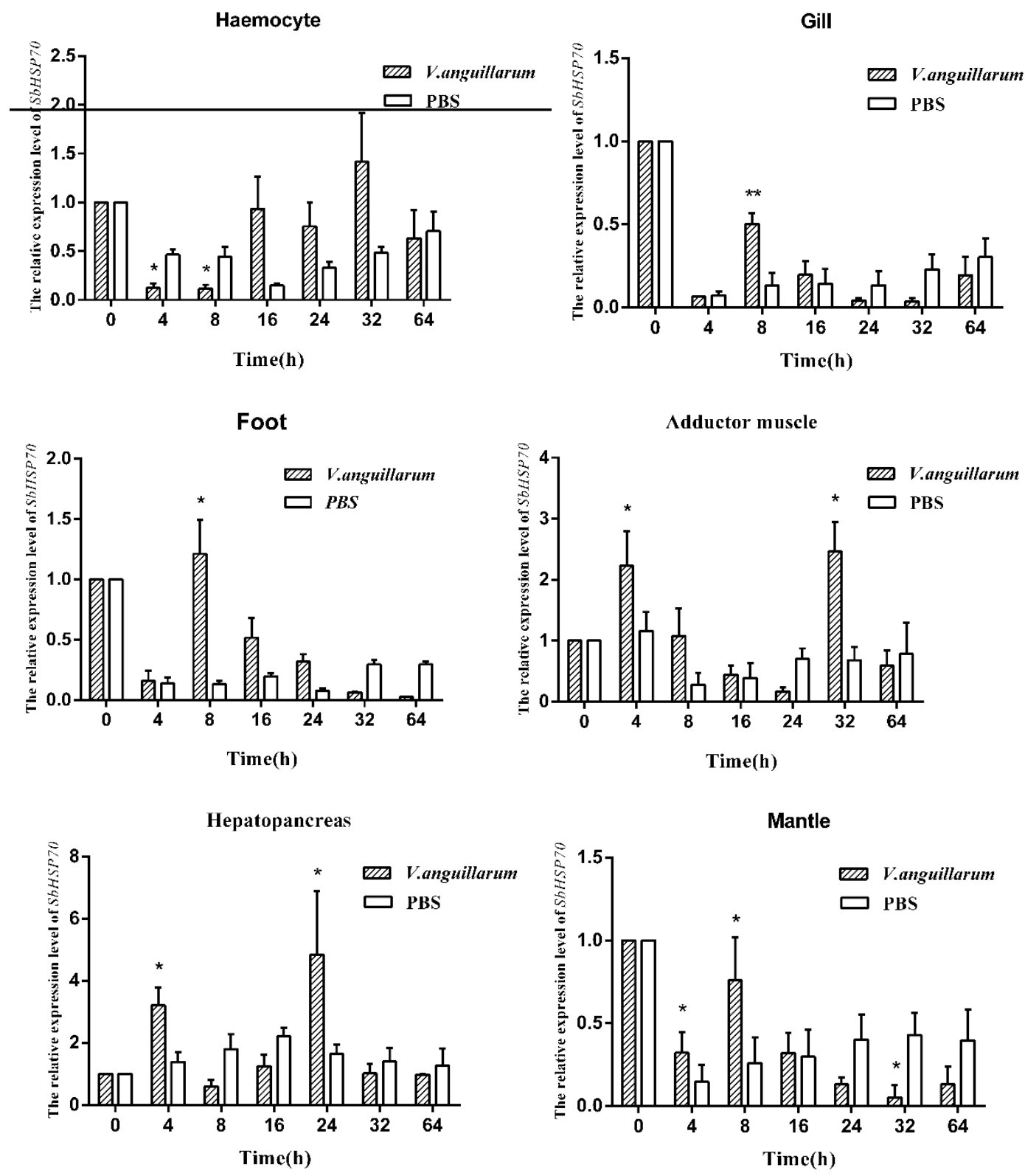

Figure 6. SbHSP70mRNA expression after $V$. anguillarum challenge in tested tissues. The mRNA expression of $S b H S P 70$ and $\beta$-actin was detected at $0,4,8,12,24,32$ and $64 \mathrm{~h}$ in treatment and control groups following challenge, respectively. The relative $\operatorname{SbHSP} 70$ expression level as exhibited by $2^{-\triangle \triangle \mathrm{Ct}}$, was determined for each group and the values were shown as means \pm S.D $(n=3)$. Two asterisks indicate highly significant differences $(p<0.01)$, one asterisk indicates significant differences $(p<0.05)$

\section{Discussion}

In recent years, studies on HSP70 have attracted an increasing amount of attention due to their multifunction in immune system, especially in the fields of tolerance elaboration of organisms. Marine mollusks, representing a certain enormous aquatic invertebrates, own extreme great economic value and important ecological effect in the food chain. More and more shellfish HSP70 genes have been identified and explored, such as $C$. hongkongensis (Zhang, 2010), A. irradians (Qu, 2004), Chlamys farreri (Qu, 2004), Patinopecten yesoensis (Qu, 2004).

In the present study, a full-length cDNA of $2423 \mathrm{bp}$ was isolated and characterized from S. broughtonii, and primary structure was also analyzed. In the analysis, key domains, conserved and signature sequences were all found in the deduced amino acids. According the previous reports, the consensus sequence GPTIEEVD was the common characteristic possessed in the C-terminus of HSP70, and of which IEEVD was a unique characteristic 
owned in common between HSP90 and HSP70 (Xie et al., 2013), which could make them form into a multiple molecular chaperone complex by regulating the connections between them, and it was a special regulatory sequence of cytoplasm (Demand et al., 1998). The structure analysis showed that this sequence existed in the $S b H S P 70$. However, only a GGFP sequence was found in the C-terminus, it was to say that the $S b H S P 70$ might be an inductive type. Deane and Woo (2005) reported that the constructive type had several GGXP sequences, while it might happen only once in the inductive type of HSP70 family in fish. These sequences were also found in other species, such as Hypena tristalis (Liu et al., 2014) and Trematomus bernacchii (Liu, 2015), and so on. Multiple alignments demonstrated that SbHSP70 shared high identity with HSP70 from other representative species, especially the T. granosa. The NJ phylogenetic analysis indicated all examined HSP70 of shellfish clustered together to form sister group. From all the obtained analysis, it suggested that the obtained HSP70 was an intact cDNA sequence of $S$. broughtonii.

qRT-PCR detected that $S b H S P 70$ mRNA distributed extensively in all examined tissues including gill, mantle, haemocytes, adductor muscle, mantle and hepatopancreas. The highest expression was detected in the foot, followed by haemocytes, gill, mantle, adductor muscle and hetapopancreas. The expression profile of $S b H S P 70$ was similar to that of previous reported MnSOD and ferritin gene in S. broughtonii, which no tissue specificity and the expression level was high in foot (Zheng et al., 2015; Zheng et al., 2016). Also, the expression profile regarding the dynamic change in the early developmental stage showed a similar change trend as for other reported genes like big-defensin. It demonstrated that some substances stored in eggs could be maternally-transferred to offspring, and were involved in many physiological processes especially in some key developmental point likes embryonic development and umbo larvae. It was well reflected in the profile of gene expression. According to reports, HSP70 was widely distributed even in nucleus, cytoplasm, endoplasmic reticulum and mitochondria of each cells (Renner and Waters, 2007), so HSP70 was essential to be involved in many biological processes in the tissues of organism.

HSP70 is one of the most important potential biomarkers due to its rapid response to stressors as absence of intron (Dean and Woo, 2005). Alteration of HSP70 levers were studied in many organisms under different stress. For example, HSP70 mRNA levels in the grass carps Ctenopharyn godonidella after rapid temperature increase were investigated, it showed that HSP70 increased with temperature rising until $32^{\circ} \mathrm{C}$ in muscle and gill, and decreased at $34^{\circ} \mathrm{C}$, which illustrated HSP70 was sensitive to high temperature challenge in grass carp (Zhou et al., 2013). In this study, it was clear from the qRT-PCR results that $V$. anguillarum challenge could lead to significant changes of SbHSP70 in examined tissues, which revealed SbHSP70 was closely involved in the immune process of anti-infection to bacterium $V$. anguillarum. However, several different change manners were observed in the tested tissues and most changes were in a time-dependent manner. The situation was also found in some previous reports. The HSP70 mRNA level was higher in hepatopancreas and muscle after stimulation with the temperature, $\mathrm{pH}$ and $\mathrm{NH}_{4} \mathrm{Cl}$ in Exopalaemon carinicauda, and the response time in hepatopancreas was earlier than that in muscle, and what's more, HSP70 mRNA expressions were inhibited with longer stress time (Han et al., 2011). Probably, that might because the HSP70 played different roles in distinct tissues including repairing, increasing, reducing synthesis as a response to cellular damage for protecting organism. The mechanism needs to be further studied and clarified.

In summary, the full-length cDNA of $S b H S P 70$ was cloned and the predicted protein showed common features with HSP70 of many other mollusks reported. This study highlights that the HSP70 has an acute response to the bacterial challenge, opening a new insight into understanding the roles of HSP70 in S. broughtonii.

\section{Acknowledgements}

This study was supported by National Natural Science Foundation of China (31602142), Central Public-interest Scientific Institution Basal Research Fund, YSFRI, CAFS (20603022017002, NO.2018GH10).

\section{References}

Bai, C. M., Gao., W. H., Wang, C. M., Yu, T., Zhang, T. W., Qiu, Z. X., Wang, Q. C., \& Huang, J. (2016). Identification and characterization of ostreid herpesvirus 1 associated with massive mortalities of Scapharca broughtonii broodstocks in china. Diseases of Aquatic Organisms, 118(1), 65-75.

Boston, R. S., Viitanen, P. V., \& Vierling, E. (1996). Molecular chaperones and protein folding in plants. Plant Molecular Biology, 32(1-2), 191-222.

Deane, E. E., \& Woo, N. Y. S. (2005). Cloning and characterization of the hsp70 multigene family from silver sea bream: modulated gene expression between warm and cold temperature acclimation. Biochemical \& Biophysical Research Communications, 330(3), 776-83. 
Demand, J., Lüders, J., \& Höhfeld, J. (1998). The carboxy-terminal domain of hsc70 provides binding sites for a distinct set of chaperone cofactors. Molecular \& Cellular Biology, 18(18), 2023-8.

Fink, A. L. (1999). Chaperone-mediated protein folding. Physiological Reviews, 79(2), 425-49.

Han, J. Y., Li, J., Li, J. T., Chang, Z. Q., Chen, P., \& Li, H. (2011). Cloning and expression of heat shock protein 70 (HSP70) of Exopalaemon carinicauda. Journal of Fisheries of China, 35(8), 1130-1138.

Kiang, J. G., \& Tsokos, G. C. (1998). Heat shock protein 70 kDa: molecular biology, biochemistry, and physiology. Pharmacology \& Therapeutics, 80(2), 183-201.

Kothary, R. K., Burgess, E. A., \& Candido, E. P. M. (1984). The heat-shock phenomenon in cultured cells of rainbow trout hsp70 mrna synthesis and turnover. Biochimica et Biophysica Acta (BBA) - Gene Structure and Expression, 783(2), 137-143.

Lewis, S., Donkin, M. E., \& Depledge, M. H. (2001). Hsp70 expression in Enteromorpha intestinalis, (chlorophyta) exposed to environmental stressors. Aquatic Toxicology, 51(3), 277-291.

Li, M., Zhu, L., Zhou, C. Y., Sun, S., Fan, Y. J., \& Zhuang, Z. M. (2012). Molecular characterization and expression of a novel big defensin (Sb-BDef1) from ark shell, Scapharca broughtonii. Fish \& Shellfish Immunology, 33(5), 1167-1173.

Li, Q. B., \& Guy, C. L. (2001). Evidence for non-circadian light/dark-regulated expression of hsp70s in spinach leaves. Plant Physiology, 125(4), 1633-42.

Liu, L., Han, L. L., Pang, C. J., \& Zhao, K. J. (2014). Identification and characteristic analysis of the heat shock protein 70 of hypena tristalis (lepidoptera: noctuidae). Research on Crops, 15(1),275.

Liu, X. R. (2015). Gene Cloning, Sequence Analysis and Cold Adaptation Studies on Hsp70 and Hsp90ß Genes from Chionodraco hamatus and Trematomus bernacchii. Shanghai Ocean University.

Livak, K. J., \& Schmittgen, T. D. (2001). Analysis of relative gene expression data using real-time quantitative PCR and the 2 $-\Delta \Delta \mathrm{ct}$ method. Methods, 25(4), 402-408.

Mager, W. H., Boer, A. H. D., Siderius, M. H., \& Voss, H. P. (2000). Cellular responses to oxidative and osmotic stress. Cell Stress \& Chaperones, 5(2), 73-5.

Mayer, M. P., \& Bukau, B. (2005). Hsp70 chaperones: cellular functions and molecular mechanism. Cellular \& Molecular Life Sciences Cmls, 62(6), 670-84.

Morimoto, R. I., Kline, M. P., Bimston, D. N., \& Cotto, J. J. (1997). The heat-shock response: regulation and function of heat-shock proteins and molecular chaperones. Essays in Biochemistry, 32, 17-29.

Qu, L. Y. (2004). Expression under adversity and cloning analysis of a heat shock protein70 (HSP70) in three species of cultured scallop. The Institute of Oceanology, Chinese Academy of Sciences.

Renner, T., \& Waters, E. R. (2007). Comparative genomic analysis of the hsp70s from five diverse photosynthetic eukaryotes. Cell Stress \& Chaperones, 12(2), 172-85.

Rizhsky, L., Liang, H., \& Mittler, R. (2002). The combined effect of drought stress and heat shock on gene expression in tobacco. Plant Physiology, 130(3), 1143-51.

Snyder, M. J., Girvetz, E., \& Mulder, E. P. (2001). Induction of marine mollusc stress proteins by chemical or physical stress. Archives of Environmental Contamination \& Toxicology, 41(1), 22-29.

Sørensen, J. G., \& Loeschcke, V. (2001). Larval crowding in drosophila melanogaster induces hsp70 expression and leads to increased adult longevity and adult thermal stress resistance. Journal of Insect Physiology, 47(11), 1301-1307.

Tanaka, K., Namba, T., Arai, Y., Fujimoto, M., Adachi, H., Sobue, G., Takeuchi, K., Nakai, A., \& Mizushima, T. (2007). Genetic evidence for a protective role for heat shock factor 1 and heat shock protein 70 against colitis. Journal of Biological Chemistry, 282(32), 23240-52.

Wu, B., Liu, Z. H., Zhou, L. Q., Ji, G. D., \& Yang, A. G. (2015). Molecular cloning, expression, purification and characterization of vitellogenin in scallop Patinopecten yessoensis with special emphasis on its antibacterial activity. Developmental \& Comparative Immunology, 49(2), 249-258.

Xie, Y. H., Wen, C. G., \& Hu, B. Q. (2013). Cloning and expression of heat shock protein 90 gene of fresh water mussel: cristaria plicata. Fish \& Shellfish Immunology, 34(6), 1748. 
Zhang, Z. H. (2010). Clone of heat shock protein70 (HSP70) genes in (Crasssostrea Hongkongensis) and response of the HSC70 gene to pollutants. Doctoral Dissertation of Jinan University.

Zhao, Q. (2018). Molecular Cloning and Functional Analysis of Hemoglobin Genes from Ark Shell Scapharca Broughtonii. Master Dissertation of Shanghai Ocean University.

Zheng, L. B., Liu, Z. H., Wu, B., Dong, Y. H., Zhou, L. Q., Tian, J. T., Sun, X. J., \& Yang, A. G. (2016). Ferritin has an important immune function in the ark shell Scapharca broughtonii. Developmental \& Comparative Immunology, 59, 15-24.

Zheng, L. B., Wu, B., Liu, Z. H., Tian, J. T., Yu, T., Zhou, L. Q., Sun, X. J., \& Yang, A. G. (2015). A manganese superoxide dismutase (MnSOD) from ark shell, Scapharca broughtonii: molecular characterization, expression and immune activity analysis. Fish \& Shellfish Immunology, 45(2), 656-665.

Zhou, X., Dong, Y. W., Wang, F., \& Dong, S. L. (2013). Effect of rapid temperature change on expression of hsp70 and hsp90 in grass carp (Ctenopharyngodon idella). Journal of Ocean University of China, 37(2), 216-221.

\section{Copyrights}

Copyright for this article is retained by the author(s), with first publication rights granted to the journal.

This is an open-access article distributed under the terms and conditions of the Creative Commons Attribution license (http://creativecommons.org/licenses/by/4.0/). 